\title{
VARIABILIDADE ESPACIAL DE ATRIBUTOS FÍSICOS DE UM ARGISSOLO VERMELHO-AMARELO CULTIVADO COM LEGUMINOSAS CONSORCIADA COM A SERINGUEIRA $\left({ }^{1}\right)$
}

\author{
SIDNEY ROSA VIEIRA $\left({ }^{2 *}\right)$; SANDRO ROBERTO BRANCALIÃO $\left({ }^{2}\right)$; \\ CÉLIA REGINA GREGO $\left({ }^{3}\right)$; ANTONIO LÚCIO MELLO MARTINS $\left({ }^{4}\right)$
}

\begin{abstract}
RESUMO
O objetivo deste trabalho foi avaliar a distribuição espacial de alguns atributos físicos do solo e verificar suas alterações no desenvolvimento da seringueira consorciada com leguminosas. O experimento foi instalado em Argissolo Vermelho-Amarelo no Polo Regional de Desenvolvimento Tecnológico dos Agronegócios do Centro-Norte, localizado em Pindorama (SP). Foram avaliadas: infiltração de água a 0,10 e a $0,20 \mathrm{~m}$ de profundidade, macro e micro porosidade e densidade do solo nas camadas 0-0,10; 0,100,20; 0,20-0,40 e 0,40-0,60 m. O desenvolvimento das plantas de seringueira foi avaliado medindo-se o perímetro do caule e o aumento desta medida no período de quatro anos (1996-1999). Os dados foram submetidos à análise de estatística descritiva para verificação de parâmetros de tendência central e dispersão. Foram utilizados métodos geoestatísticos incluindo semivariogramas, krigagem e mapas de isolinhas para a avaliação da variabilidade espacial. Houve dependência espacial de moderada a forte para todos os atributos do solo, com o valor do alcance variando entre 15 e $90 \mathrm{~m}$. A dependência espacial anotada para infiltração de água no solo não teve relação com as avaliações efetuadas nas plantas nem com os outros atributos avaliados. Os altos valores de densidade do solo e de microporosidade na camada de 0,20-0,40 m indicaram a ocorrência de compactação nesta camada. O perímetro do caule de seringueira aumentou linearmente com o tempo, porém a taxa de crescimento do perímetro do caule decresceu ao longo dos anos. A taxa média de crescimento do perímetro do caule variou em função do crescimento menor no inverno quando comparado com o do verão. Na distribuição espacial do espessamento do caule das árvores de seringueira ao longo do tempo houve alta continuidade, avaliada pelos baixos valores do efeito pepita dos semivariogramas e estreita correlação com densidade do solo, onde locais menos densos tiveram os maiores valores para o perímetro do caule da seringueira.
\end{abstract}

Palavras-chave: Infiltração de água no solo, condutividade hidráulica, física do solo, heveicultura.

(1) Recebido para publicação em 8 de junho de 2009 e aceito em 21 de janeiro de 2010.

$\left(^{2}\right)$ Centro de Pesquisa e Desenvolvimento de Solos e Recursos Ambientais, Caixa Postal 28, 13001-970 Campinas (SP). E-mail: sidney@iac.sp.gov.br $\left(^{*}\right)$ Autor correspondente; brancaliao@iac.sp.gov.br

$\left.{ }^{3}\right)$ Embrapa Monitoramento por Satélite, Av. Soldado Passarinho, 303, 13070-115 Campinas (SP). E-mail: crgrego@cnpm.embrapa.br.

(4) Polo Regional de Desenvolvimento Tecnológico do Centro-Norte/APTA, Caixa Postal 24, 15830-000 Pindorama (SP). E-mail: lmartins@apta.sp.gov.br 


\title{
ABSTRACT \\ SPATIAL VARIABILITY OF SOIL PHYSICAL ATTRIBUTES ON AN ALFISOL CULTIVATED WITH LEGUMINOUS CROPS UNDER RUBBER TREES
}

\begin{abstract}
The aim of this study was to evaluate the spatial variability of some soil physical attributes and its effects on the development of rubber trees cultivated with leguminous cover crops. The experiment was conducted at Pólo Regional de Desenvolvimento Tecnológico dos Agronegócios do Centro Norte, located in Pindorama, SP, Brazil, on a Typic Kandiudalf. Saturated infiltration rate was evaluated at 0.10 and $0.20 \mathrm{~cm}$ depth while macro and micro porosity and bulk density were evaluated at $0-0.10,0.10-0.20$, 0.20-0.40 and 0.40-0.60 m layer. Rubber tree plant development was evaluated for four years (1996-1999) through plant stem perimeters and its increase with time. Descriptive statistics was used to calculate and analyze the dispersion and central limit parameters. Geostatistics was used to evaluate the spatial dependence through semivariograms, to perform interpolation using kriging and to construct contour maps for georeferenced data. Spatial dependence was found for all soil physical properties with the range of spatial dependence varying between 15 and $90 \mathrm{~m}$. Saturated infiltration rate showed spatial dependence with no relation with plant development evaluations or with any other soil physical attributes. High values for bulk density and micro porosity at $0.20-0.40 \mathrm{~m}$ indicate soil compaction at this layer. The plant stem perimeter increased linearly with time while the rate of increase in perimeter decreased with time. The mean increase in plant perimeter was smaller for the winter as compared with the summer measurements. The spatial distribution for rubber tree growth as a function of time presented high continuity as measured by the low nugget effect values and it showed close relation with bulk density values, as the regions with low bulk density showed large values for rubber tree stem perimeter.
\end{abstract}

Key words: Infiltration rate, hydraulic conductivity, hevea brasiliensis, soil physical properties

\section{INTRODUÇÃO}

A seringueira pertence ao gênero Hevea, da família Euphorbiaceae e na Ásia é plantada como a principal fonte de borracha natural. A área total estimada de seringueira plantada no mundo é superior a nove milhões de hectares sendo tradicionalmente cultivada na região equatorial entre as latitudes de $10^{\circ}$ Norte e $10^{\circ} \mathrm{Sul}$. O Estado de São Paulo possui 14 milhões de hectares aptos à heveicultura, e desse total, atualmente 90 mil hectares estão ocupados com seringais (APABOR, 2003), conferindo ao Estado a condição de primeiro produtor de borracha natural do Brasil, contribuindo com 55\% da produção do país.

Culturas de cobertura como o kudzu-tropical (Pueraria phaseoloides Benth.) têm sido utilizadas como opção de sistema de manejo de solo visando à diminuição das capinas, a conservação da umidade do solo e outros benefícios advindos do uso de leguminosas como planta de cobertura (CARDOso, 1989). Nuernberg (1986) evidenciou os efeitos benéficos do consórcio da seringueira com leguminosas nas propriedades físicas do solo.

Entretanto, são escassas as pesquisas relacionadas ao manejo na entrelinha da seringueira nas áreas tradicionais de cultivo em trabalhos de longa duração. CENTURIon et al., (2004) avaliaram o manejo de culturas de cobertura na entrelinha da seringueira, durante oito anos de cultivo e verificaram que os atributos físicos do solo foram afetados, especialmente a porosidade e a densidade do solo, e as maiores alterações em função do manejo da entrelinha da seringueira manifestaram-se na camada superficial (0$0,20 \mathrm{~m})$.

Os atributos de planta, quando amostrados de maneira que as posições espaciais de onde as amostras foram feitas sejam conhecidas, revelam variabilidade decorrente, de alguma maneira, do somatório da variabilidade dos atributos físicos, químicos e biológicos do solo. Os fatores de formação do solo atuam naturalmente e variam, de acordo com a escala de trabalho, de alguns metros quadrados até milhares de hectares, fazendo com que os atributos do solo não se organizem ao acaso e sim com alguma estruturação espacial. GREGo e VIEIRA (2005), em uma parcela experimental de $30 x$ $30 \mathrm{~m}$, verificaram grande variabilidade dos atributos físicos do solo, mesmo que a parcela fosse considerada homogênea poderia mascarar os resultados dos tratamentos aplicados. Quando isto ocorre, os atributos medidos são de alguma maneira relacionados com seu vizinho, ou seja, existe dependência espacial entre as amostras, possibilitando a aplicação de geoestatística para avaliar a variabilidade dos vários fatores que contribuem para o crescimento e a produtividade das plantas (Vieira et al., 1983; VieIRA, 2000).

Dentro desse enfoque, o objetivo deste trabalho foi avaliar o desenvolvimento da seringueira e verificar as alterações de alguns atributos físicos do solo, utilizando-se métodos da geoestatística. 


\section{MATERIAL E MÉTODOS}

O experimento foi instalado em Pindorama (SP), cujas coordenadas geográficas são $21^{\circ} 13^{\prime}$ de latitude sul e $48^{\circ} 55^{\prime}$ de longitude oeste. Conforme a classificação de Köeppen, o clima enquadra-se no tipo Aw, definido como tropical úmido com estação chuvosa no verão e seca no inverno. O solo da área em estudo foi classificado como Argissolo Vermelho-Amarelo (EMBrapa, 2006). O relevo da região é ondulado com altitudes que variam de 498 a $594 \mathrm{~m}$.

A cultura de seringueira analisada foi submetida à enxertia com a cultivar PB 235 e como cultura intercalar foram semeadas leguminosas perenes (Centrosema, Galáxia, Soja perene, Guatá e Kudzu tropical) um mês antes da enxertia. O espaçamento das plantas de seringueiras foi de 7,00 x 3,00 m, perfazendo área total do experimento de 2,1 ha. Os tratos culturais na seringueira foram efetuados conforme recomendações de CARDoso (1989), e o preparo de solo nas entrelinhas consistiu de duas gradagens.

Durante o período de desenvolvimento da seringueira foram avaliados os atributos físicos do solo e de desenvolvimento das plantas. A infiltração de água do solo foi medida com permeâmetro IAC a 0,10 e a $0,20 \mathrm{~m}$ de profundidade, usando os procedimentos descritos em VIEIRA (1998), em uma malha de 140 pontos (Figura 1 a), sendo cinco pontos espaçados de 4 em 4 metros em cada uma das 28 parcelas. O desenvolvimento das plantas foi avaliado através de medições do diâmetro do caule à altura do peito, em 5/1996, 4/1997, 11/1997, 5/1998, 11/ 1998, 5/1999 e 11/1999 na malha de 28 pontos (Figura 1 b). A partir destes dados foram calculados os resultados do crescimento anual do caule $(\mathrm{cm})$, segundo metodologia descrita por JORGE (2005). Foram retiradas amostras em anéis volumétricos de $100 \mathrm{~cm}^{3}$ nas camadas $0-0,10 \mathrm{~m}, 0,10-0,20 \mathrm{~m}, 0,20-0,40$ $\mathrm{m}$ e $0,40-0,60 \mathrm{~m}$ em 28 pontos (Figura 1c) com as quais foram determinadas a macro e microporosidade e densidade do solo, usando o método descrito em CAMARGo et al., (1986).

A área foi demarcada, inicialmente, com delineamento casualizado com sete tratamentos e quatro repetições (28 parcelas)- cinco tratamentos com leguminosas perenes e dois com vegetação espontânea e um sem vegetação. A estatística utilizada para análise deste delineamento parte do princípio de que existe aleatoriedade nos dados, ou seja, pressupõe que os dados sejam independentes uns dos outros (SNedecor e Cochran, 1967). Os parâmetros da estatística descritiva foram calculados com o programa STAT, descrito em Vieira et al., (2002) com a finalidade de avaliar parâmetros de tendência central e de dispersão em torno dos valores médios. Os cálculos de geoestatística, compreendendo o semivariograma e as interpolações por krigagem foram efetuados com programas do pacote GEOEST descrito em VIEIRA et al., (2002). Todos os modelos de semivariograma foram submetidos à validação pelo método Jack knifing, segundo descrito em VIEIRA (2000). Este procedimento garante que os mapas produzidos tenham validades iguais, indiferente de o número original de amostras ter sido igual ou diferente, uma vez que a validação por este método estima valores medidos para todos os locais do campo (VIEIRA et al., 1983). Dessa maneira, os mapas foram construídos com valores interpolados por krigagem usando o programa Surfer 7.0 (GOLDEN SOFTwARE, 1999).
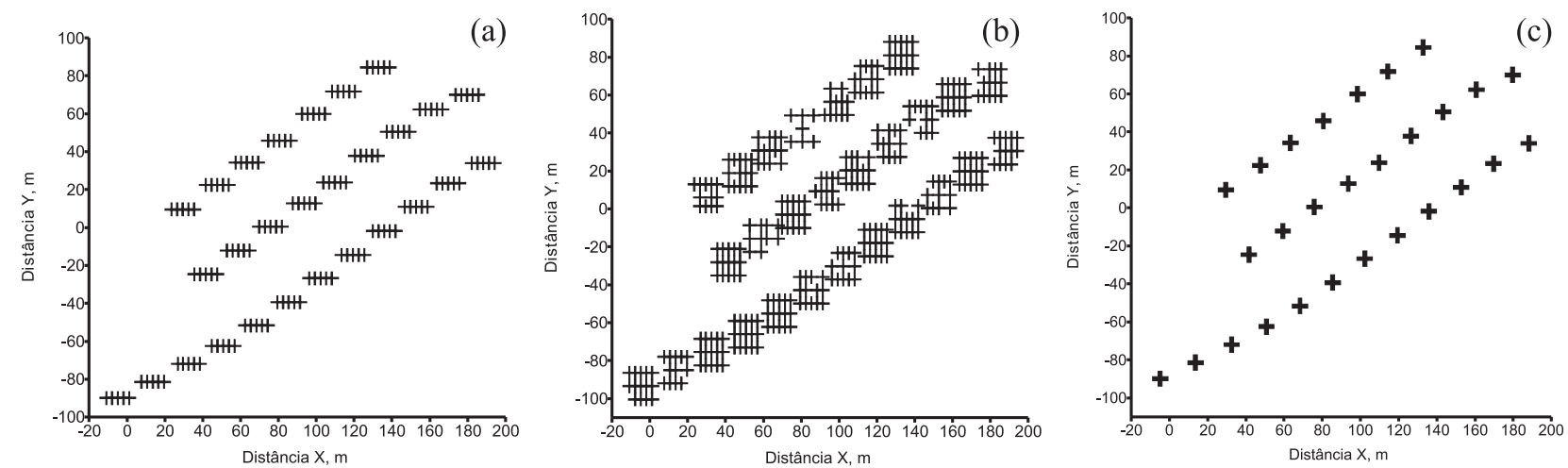

Figura 1. Malha de amostragem: a) Medição de infiltração de água (140 pontos); b) Medição de diâmetro do caule das plantas (366 pontos); c) Coleta de anéis para determinação de porosidade e densidade do solo (28 pontos). 


\section{RESULTADOS E DISCUSSÃO}

Verifica-se que houve grande variação em profundidade para os valores médios de infiltração (de 32,65 para 101,10 $\mathrm{mm} \mathrm{h}^{-1}$ ) em 1994 (Tabela 1). Considerando que não houve nenhuma operação agrícola de preparo ou cultivo nesta área algum outro fator pode ter afetado os valores de infiltração a 0,20 $\mathrm{m}$. Acredita-se que este fato seja devido à amostragem relativa à grande sensibilidade do permeâmetro utilizado para as medições de infiltração. O valor máximo para infiltração a 0,20 m em $1994\left(630,90 \mathrm{~mm} \mathrm{~h}^{-1}\right)$ ocorreu em apenas um ponto no campo; houve um valor de $570,70 \mathrm{~mm} \mathrm{~h}^{-1}$ e a maioria dos outros valores são próximos do valor médio $\left(101,10 \mathrm{~mm} \mathrm{~h}^{-1}\right)$. A infiltração de água no solo é, normalmente, bastante variável devido a integrar variações de textura e estrutura do solo, variações resultantes de manejo do solo e também aquelas advindas de infiltração em orifícios deixados por organismos como minhocas, formigas e cupins ou por raízes mortas. Assim, este é um resultado bastante normal para medições de infiltração de água cujas distribuições são comumente assimétricas tendo assim uma grande quantidade de valores baixos e alguns valores tão altos que contribuem para elevar o valor médio. Nestas condições é possível que o valor médio não represente adequadamente a população. VIEIRA et al., (1981) relata resultados bastante semelhantes a estes para um conjunto de 1280 valores de infiltração. A infiltração para $0,10 \mathrm{~cm}$ em 1998 foi bastante semelhante à de 1994 para praticamente todos os parâmetros estatísticos (Tabela 1). Na profundidade $0,10 \mathrm{~m}$, embora tenha ocorrido acréscimo pequeno para o valor médio da infiltração de água no solo, houve um acréscimo acentuado no coeficiente de variação, indicando um aumento na variabilidade para estas medições nesta profundidade. Segundo Guedes Filho (2009), pode-se atribuir os altos coeficientes de variação para a condutividade hidráulica do solo saturado ao efeito local. SIQUeIRA (2006) e Guedes Filho (2009), avaliando a condutividade hidráulica do solo saturado também constataram altos valores do coeficiente de variação. Os autores mencionam que o fato se deve especialmente à alta variabilidade espacial dos solos, típico das propriedades de movimentação tridimensional da água.

Tabela 1. Parâmetros de estatística descritiva da infiltração de água no solo

\begin{tabular}{lcccccccc}
\hline Variável & Número & Média & Variância & CV & Mínimo & Máximo & Simetria & Curtose \\
\cline { 2 - 8 } & & & & & mm h h $^{-1}$ & & & \\
$1994(0,10 \mathrm{~m})$ & 140 & 32,65 & 457,20 & 65,48 & 5,09 & 179,90 & 2,72 & 17,55 \\
$1994(0,20 \mathrm{~m})$ & 139 & 101,10 & 9127,00 & 94,51 & 5,73 & 630,90 & 2,96 \\
$1998(0,10 \mathrm{~m})$ & 140 & 37,07 & 1175,00 & 92,49 & 3,44 & 240,90 & 2,87 & 14,83 \\
$1998(0,20 \mathrm{~m})$ & 140 & 29,82 & 639,80 & 84,82 & 6,45 & 185,00 & 2,84 & 14,63 \\
\hline
\end{tabular}

Tendo em vista o alto coeficiente de variação e os altos coeficientes de simetria e de curtose, podese dizer que a infiltração de água no solo teve distribuição diferente da normal (Tabela 1). Esse processo ocorre principalmente devido à natureza desta medição ser bastante variável de um ponto para outro, dependendo das condições e do tipo de solo em que as medições são feitas. Pode ter ocorrido devido à distribuição bastante localizada dos valores de infiltração, ou seja, alguns pontos com valores muito altos ou muito baixos. Este resultado concorda com os observados por Nielsen et al. (1973), contudo, discordam de VIEIRA et al. (1981), quando notaram que houve distribuição normal de frequência para infiltração de água no solo. De acordo com Journel E Huijbregts (1978) são necessários que os dados tenham distribuição normal para aplicações de geoestatística. Uma vez que o objetivo deste trabalho foi avaliar a existência de relações espaciais entre o crescimento da seringueira e propriedades do solo usando a geoestatística, não se buscou identificar a distribuição de frequência dos dados. Os parâmetros simetria e curtose simplesmente foram avaliados para se ter uma indicação se os dados se aproximam ou não da distribuição normal para auxiliar nas discussões sobre a ocorrência de uma grande quantidade de valores baixos juntamente com alguns valores muito altos, resultados indicados por altos coeficientes de simetria e de curtose. Quanto a macroporosidade, microporosidade e densidade do solo (Tabela 2), os coeficientes de simetria e de curtose indicam que houve uma proximidade da distribuição normal de frequências.

Na figura 2, verifica-se que o aumento dos valores médios para o perímetro do caule da seringueira resultou no decréscimo dos valores de coeficientes de variação, indicando que o crescimento das plantas causou uniformização dos seus diâmetros. As 
distribuições de frequências foram normais para a maioria dos dados de perímetro do caule e incremento (variação anual desse perímetro do caule). Nota-se também que os valores médios para incremento variam em função do crescimento menor no inverno quando comparado com o do verão. Vale também ressaltar que o perímetro do caule cresceu linearmente e o incremento decresceu da mesma forma ao longo dos anos.

Os semivariogramas (Figura 3) de infiltração de água confirmam que os resultados variam de maneira diferente no espaço, ao longo dos anos e em profundidade. Esse processo pode ser visto pelos diferentes parâmetros e modelos ajustados aos semivariogramas, os quais descrevem a variabilidade espacial, que foram: esféricos a 0,10 e a $0,20 \mathrm{~m}$ em 1994, exponencial a $0,10 \mathrm{~m}$ em 1998, e esférico a 0,20 m em 1998. Verifica-se que os alcances de dependência espacial também são diferentes, variando de 15 a 40 $\mathrm{m}$, evidenciando a diferença na variabilidade espacial entre as duas amostragens nas duas profundidades.

Na figura 4, notam-se os semivariogramas escalonados para microporodidade, macroporosidade e densidade do solo nas quatro camadas. Os semivariogramas foram escalonados e ajustados ao modelo esférico. De acordo com Zimback (2001), a dependência espacial foi moderada para macroporosidade $(54,55 \%)$ e alta para microporosidade e densidade do solo, 72,73 e $78,95 \%$ respectivamente. Observa-se nos semivariogramas, a diferença do efeito pepita em relação ao patamar ser maior e mais evidente para microporosidade e densidade do solo do que para macroporosidade.

Observam-se na figura 5 os semivariogramas, escalonados para o perímetro do caule nas várias datas amostradas. Constata-se a semelhança entre os semivariogramas para as diferentes datas, indicando que a distribuição espacial do crescimento das árvores de seringueira permaneceu aproximadamente constante com o tempo, ou seja, os menores perímetros de caules em um determinado local ficaram menores durante todo o período estudado. Os semivariogramas escalonados foram ajustados a uma função exponencial resultando em uma dependência espacial moderada $(38,46 \%)$, segundo a classificação de ZІмBACK (2001).

Os mapas (Figuras 6, 7 e 8) foram construídos com os valores estimados por krigagem a cada $3 \mathrm{~m}$ para as variáveis em que havia dependência espacial detectada no semivariograma. Nota-se nos mapas com a mesma divisão de escalas (Figura 6) que a variabilidade para infiltração é bastante diferente nas duas profundidades e nas duas amostragens, e para 0,20 m em 1994, ocorreram valores muito maiores comparado com os demais mapas. Uma vez que as medições efetuadas com permeâmetro se referem ao estado de saturação dos poros do solo em condições de campo, as diferenças no teor de água do solo, na superfície e em profundidade, não contribuem para este resultado. Por outro lado, nota-se na tabela 1 que, exceto pelo valor da infiltração de água no solo a $0,20 \mathrm{~m}$ de profundidade $\left(110,10 \mathrm{mmh}^{-1}\right)$, as variações foram bastante pequenas (de 32,65 em 1994 para 37,07 em 1998).

Tabela 2. Parâmetros de estatística descritiva dos macroporos, microporos e da densidade do solo

\begin{tabular}{|c|c|c|c|c|c|c|c|c|}
\hline Variável & Num & Média & Variância & $\mathrm{CV}$ & Mínimo & Máximo & Simetria & Curtose \\
\hline & \multicolumn{8}{|c|}{$0-0,10 \mathrm{~m}$} \\
\hline Densidade $\left(\mathrm{Mg} \mathrm{m}^{-3}\right)$ & 28 & 1,55 & 0,0061 & 5,05 & 1,35 & 1,71 & $-0,251$ & 0,368 \\
\hline Macroporos $\left(\mathrm{m}^{-3} \mathrm{~m}^{-3}\right)$ & 28 & 0,15 & 0,0020 & 29,66 & 0,07 & 0,23 & 0,319 & $-1,043$ \\
\hline \multirow[t]{2}{*}{ Microporos $\left(\mathrm{m}^{-3} \mathrm{~m}^{-3}\right)$} & 28 & 0,22 & 0,0008 & 12,84 & 0,16 & 0,27 & $-0,244$ & $-0,825$ \\
\hline & \multicolumn{8}{|c|}{$0,10-0,20 \mathrm{~m}$} \\
\hline Densidade $\left(\mathrm{Mg} \mathrm{m}^{-3}\right)$ & 28 & 1,55 & 0,0061 & 5,05 & 1,35 & 1,71 & $-0,251$ & 0,368 \\
\hline Macroporos $\left(\mathrm{m}^{-3} \mathrm{~m}^{-3}\right)$ & 27 & 0,13 & 0,0010 & 23,73 & 0,09 & 0,20 & 0,657 & $-0,431$ \\
\hline \multirow[t]{2}{*}{ Microporos $\left(\mathrm{m}^{-3} \mathrm{~m}^{-3}\right)$} & 27 & 0,24 & 0,0006 & 10,62 & 0,20 & 0,33 & 1,446 & 3,430 \\
\hline & \multicolumn{8}{|c|}{ 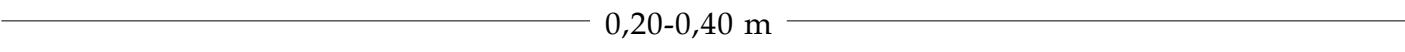 } \\
\hline Densidade $\left(\mathrm{Mg} \mathrm{m}^{-3}\right)$ & 28 & 1,60 & 0,0065 & 5,03 & 1,45 & 1,74 & $-0,003$ & $-0,703$ \\
\hline Macroporos $\left(\mathrm{m}^{-3} \mathrm{~m}^{-3}\right)$ & 28 & 0,16 & 0,0013 & 23,32 & 0,04 & 0,22 & $-0,946$ & 2,197 \\
\hline \multirow[t]{2}{*}{ Microporos $\left(\mathrm{m}^{-3} \mathrm{~m}^{-3}\right)$} & 28 & 0,23 & 0,0006 & 10,81 & 0,18 & 0,27 & $-0,450$ & $-0,668$ \\
\hline & \multicolumn{8}{|c|}{$0,40-0,60 \mathrm{~m} \longrightarrow$} \\
\hline Densidade $\left(\mathrm{Mg} \mathrm{m}^{-3}\right)$ & 28 & 1,49 & 0,0035 & 3,94 & 1,41 & 1,63 & 0,710 & $-0,019$ \\
\hline Macroporos $\left(\mathrm{m}^{-3} \mathrm{~m}^{-3}\right)$ & 28 & 0,18 & 0,0009 & 17,04 & 0,13 & 0,28 & 1,266 & 3,291 \\
\hline Microporos $\left(\mathrm{m}^{-3} \mathrm{~m}^{-3}\right)$ & 28 & 0,26 & 0,0005 & 8,37 & 0,21 & 0,30 & $-0,367$ & $-0,271$ \\
\hline
\end{tabular}



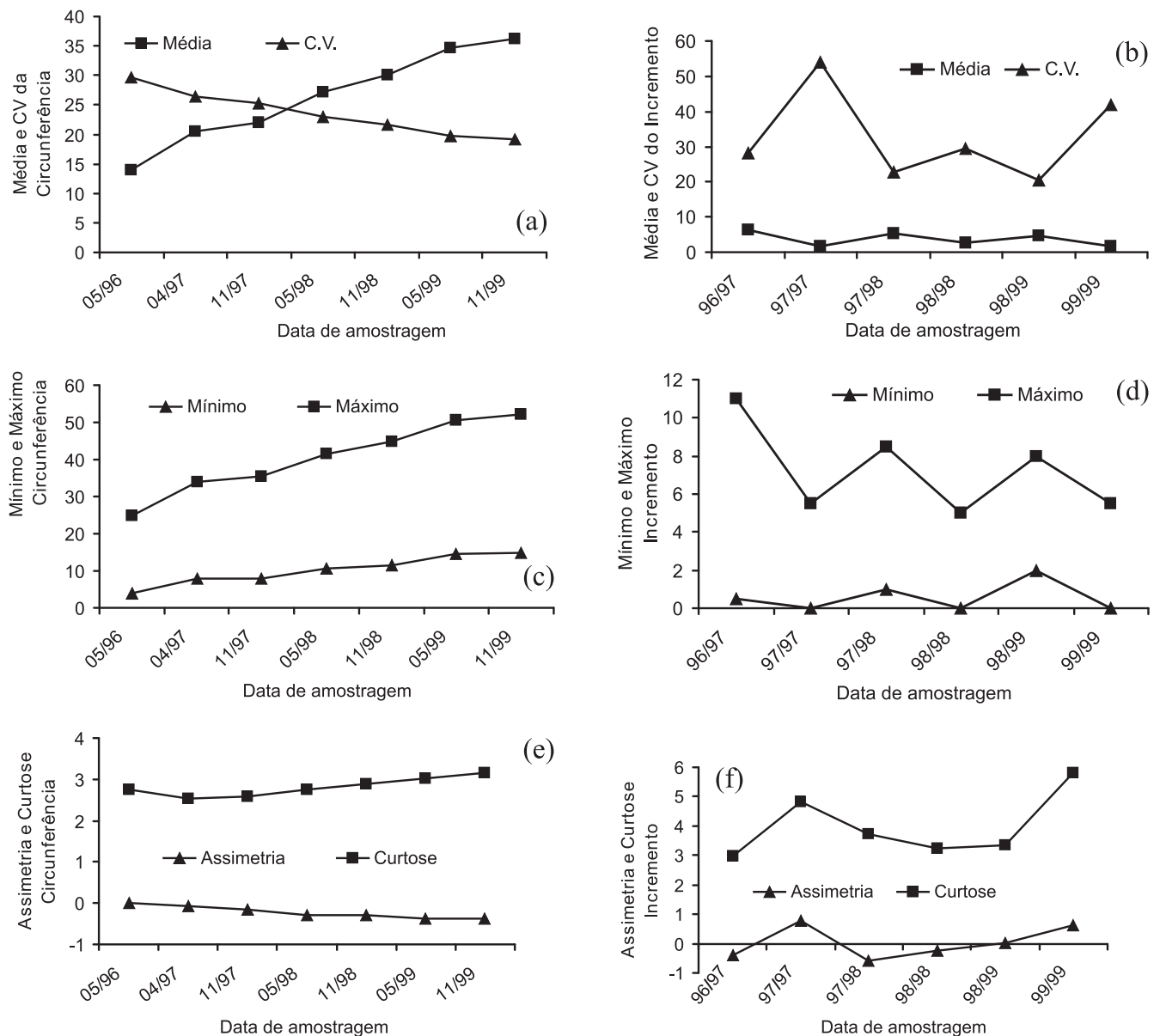

(e)

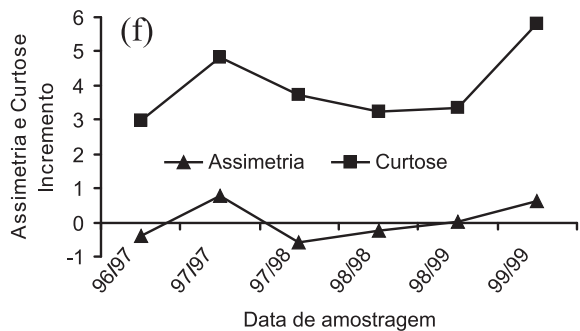

Figura 2. Evolução temporal de parâmetros estatísticos para perímetro do caule e incremento: a) Média e coeficiente de variação do perímetro do caule; b) Média e coeficiente de variação do incremento; c) Valores mínimos e máximos do perímetro do caule; d) valores mínimos e máximos do incremento, e) Simetria e curtose do perímetro do caule; f) Simetria e curtose do incremento.
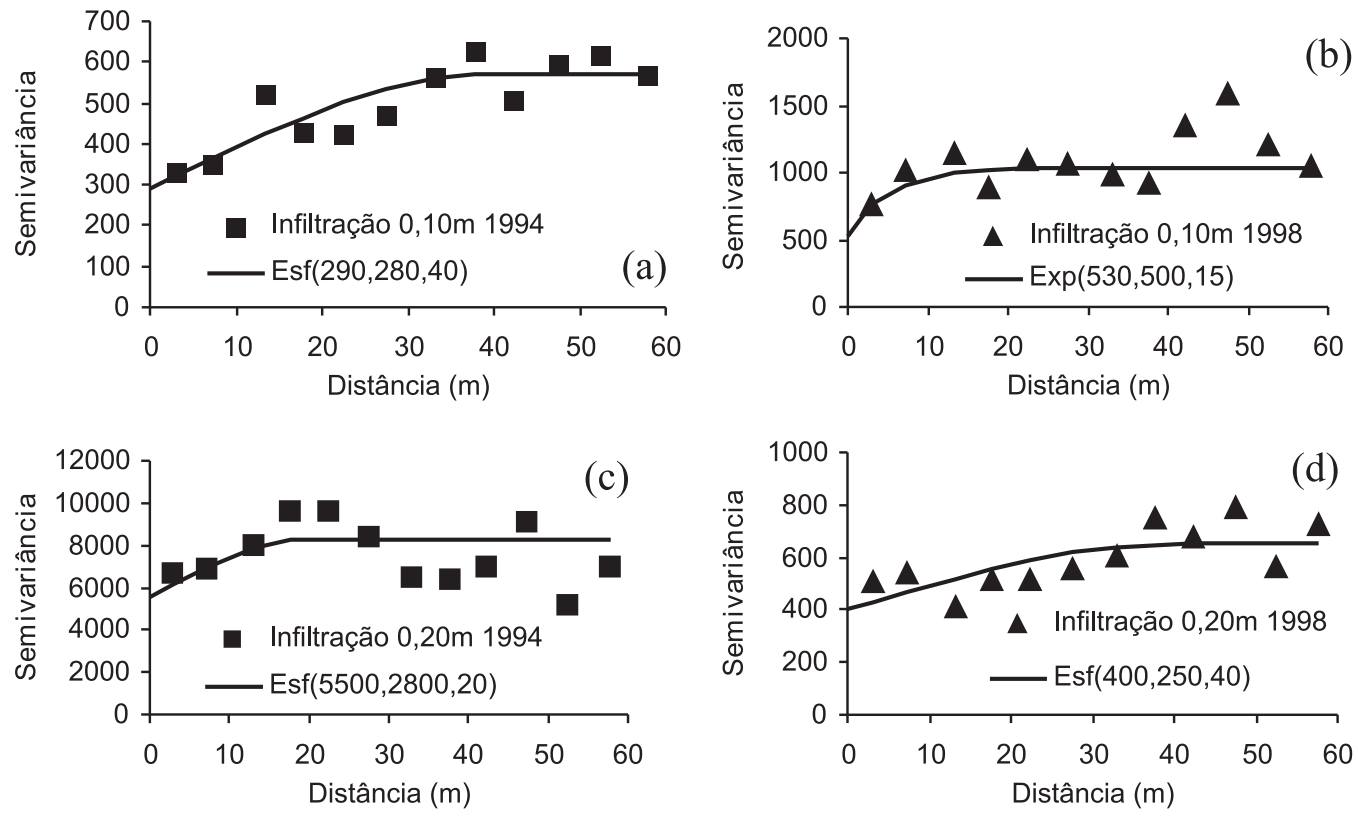

Figura 3. Semivariogramas da infiltração de água no solo: a) 0,10 m 1994; b) 0,10 m 1998; c) 0,20 m 1994 ; d) 0,20 m 1998 . 

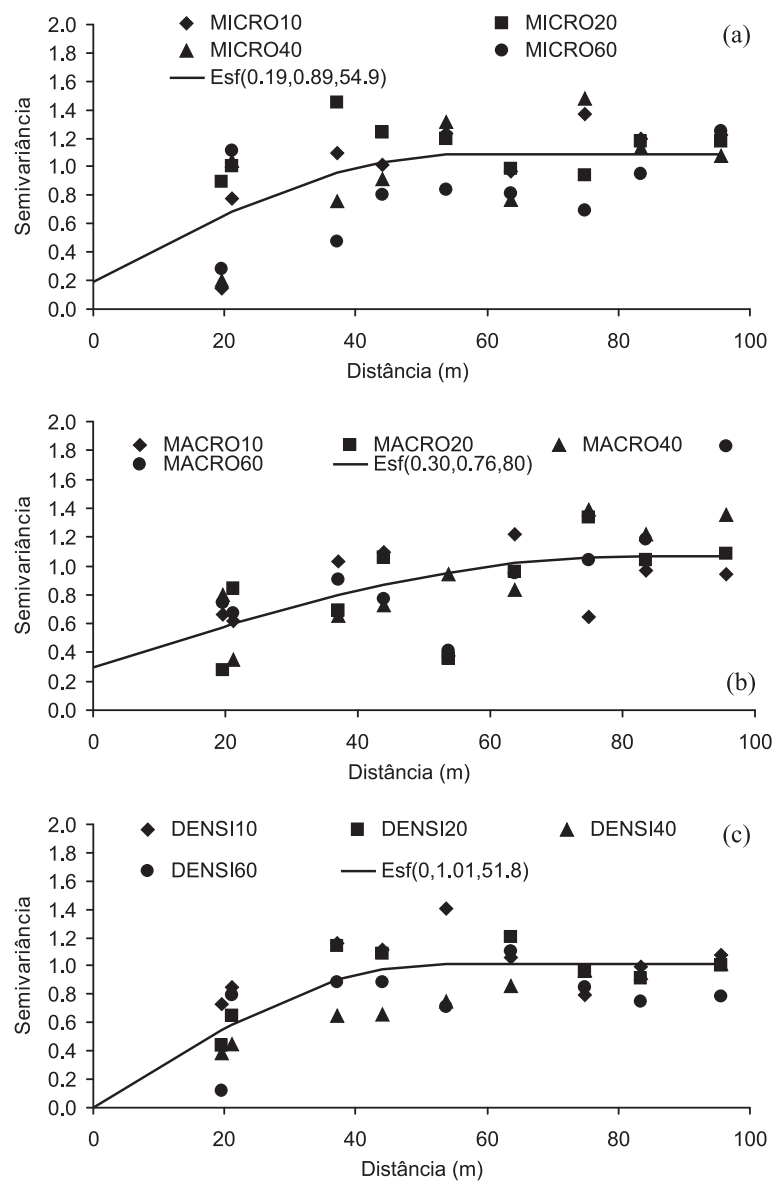

Figura 4. Semivariogramas escalonados nas camadas de $0-0,10 ; 0,10-0,20 ; 0,20-0,40,0,40-0,60 \mathrm{~cm}$ para: a) Microporosidade; b) Macroporosidade; c) Densidade do solo.

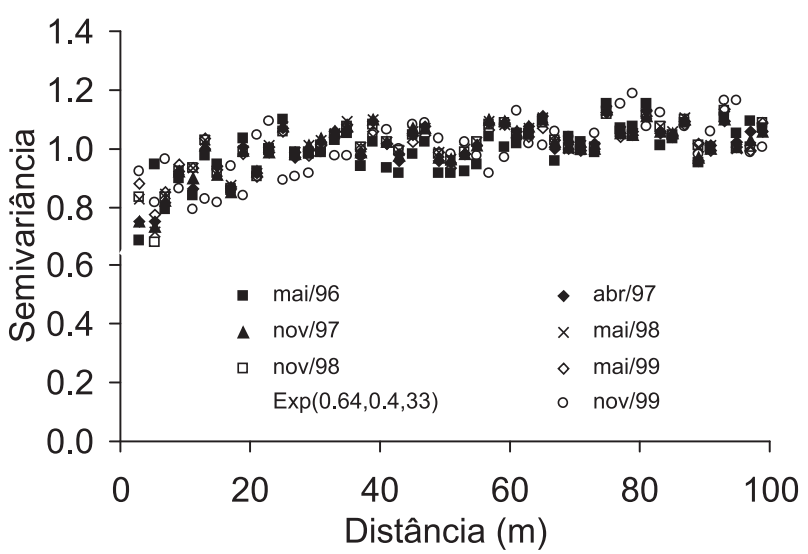

Figura 5. Semivariogramas escalonados para perímetro do caule das plantas de seringueira de 1996 a 1999. (a) Infiltração 0,10 m - 1994

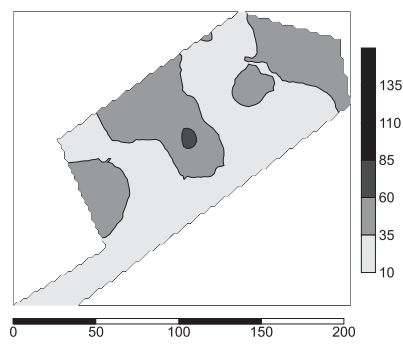

(c) Infiltração $0,20 \mathrm{~m}-1994$

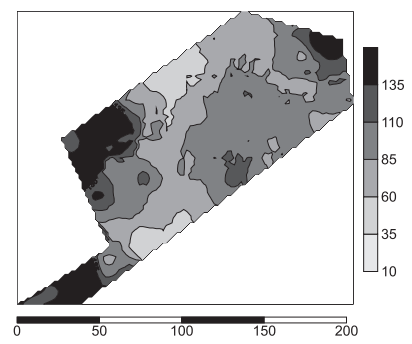

(d) Infil tração 0,20 m - 1998

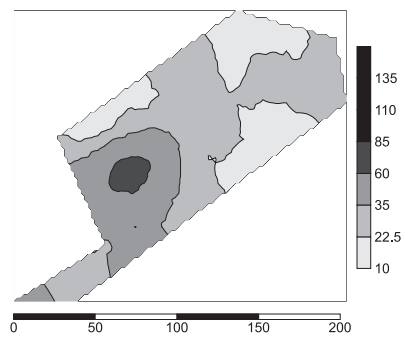

Figura 6. Mapas de isolinhas para infiltração de água $(\mathrm{mm}$ $\mathrm{h}^{-1}$ ) de 0,10 e 0,20 m de profundidade em 1994 e 1998.

Este alto valor médio ocorrido a 0,20 m em 1994 $\left(101,10 \mathrm{~mm} \mathrm{~h}^{-1}\right)$ deve-se a apenas um valor de infiltração de $630,90 \mathrm{~mm} \mathrm{~h}^{-1}$ como já discutido. Souza e Alves (2003) obtiveram valores superiores de infiltração de água para solo cultivado com seringueira, em relação aos verificados no presente trabalho, também com altos coeficientes de variação.

Os mapas de microporosidade $\left(\mathrm{m}^{3} \mathrm{~m}^{-3}\right)$, macroporosidade $\left(\mathrm{m}^{3} \mathrm{~m}^{-3}\right)$ e densidade do solo $\left(\mathrm{Mg} \mathrm{m}^{-3}\right)$ nas camadas de $0-0,10 ; 0,10-0,20 ; 0,20-0,40 ; 0,40-0,60 \mathrm{~m}$ estão apresentados na figura 7 . A microporosidade, que variou de 0,17 até $0,28 \mathrm{~m}^{3} \mathrm{~m}^{-3}$, teve praticamente a mesma variação espacial para as diferentes camadas, e de 0,40$0,60 \mathrm{~m}$ visualiza-se um aumento de microporosidade em toda a área amostrada. Os mapas de macroporosidade não possuem relação direta com os de microporosidade, apesar de que na camada superfícial $(0-0,20 \mathrm{~m})$ observamse locais com manchas de maior macroporosidade correspondendo às de menores valores de microporosidade. Os mapas de densidade do solo foram feitos também na mesma escala, variando de 1,4 a 1,7 $\left(\mathrm{Mg} \mathrm{m}^{-3}\right)$. Verifica-se que há uma densidade de solo maior em toda a área em estudo de 0,10-0,20 m e também de $0,20-0,40 \mathrm{~m}$ comparando com as demais camadas. Tanto a textura de solo quanto o manejo podem estar associados a este resultado, pois a ação das leguminosas na superfície favorece a diminuição da densidade do solo e consequente redução da compactação superficial estando de acordo com CENTURION et al., (2004) que, trabalhando com culturas de cobertura na entrelinha da seringueira, verificaram as maiores densidades e porosidades do solo na camada de 0-0,20 m. NuERNBERG (1986) também evidenciaram os efeitos benéficos do consórcio com leguminosas nas propriedades físicas do solo. 
Microporosidade $\left(\mathrm{m}^{3} \mathrm{~m}^{-3}\right)$

$0-0,10 \mathrm{~m}$
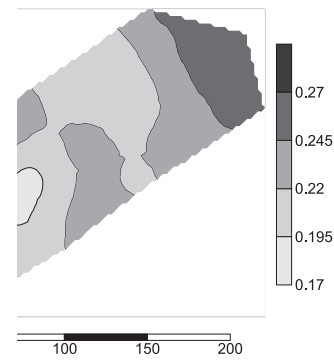

$0,10-0,20 \mathrm{~m}$

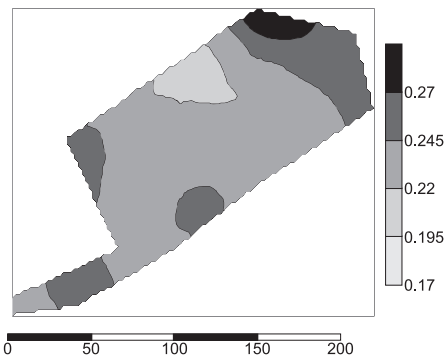

0,20-0,40 m

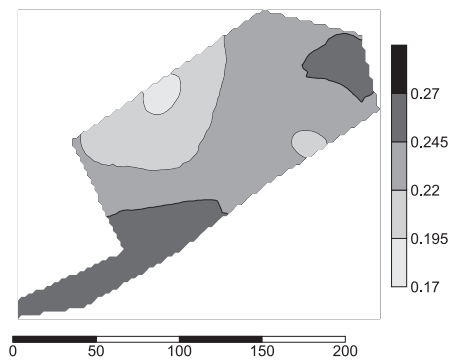

Macropmosidade $\left(\mathrm{m}^{3} \mathrm{~m}^{-3}\right)$
$0,10-0,20 \mathrm{~m}$

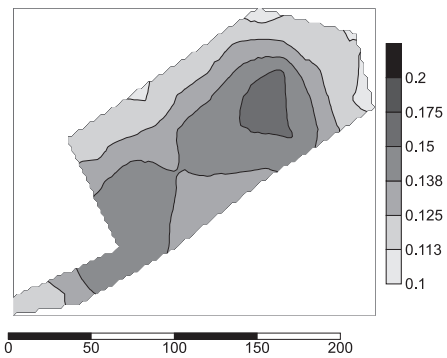

0,20-0,40 m

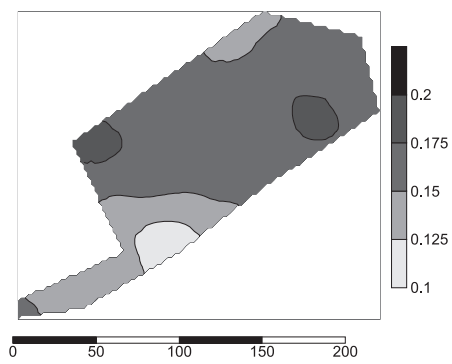

0,40-0,60m

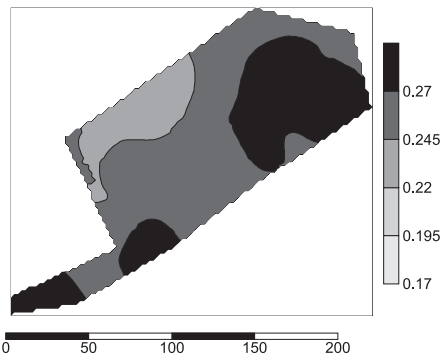

Densidade do solo $\left(\mathrm{Mg}^{3} \mathrm{~m}^{-3}\right)$

$0-0,10 \mathrm{~m}$

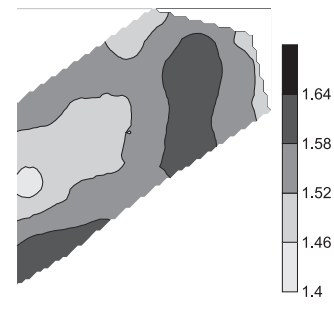

$100 \quad 150 \quad 200$

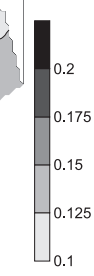

Figura 7. Mapas de isolinhas de microporosidade $\left(\mathrm{m}^{3} \mathrm{~m}^{-3}\right)$, macroporosidade $\left(\mathrm{m}^{3} \mathrm{~m}^{-3}\right)$ e densidade do solo $\left(\mathrm{Mg} \mathrm{m}^{-3}\right)$ nas camadas de $0-0,10 ; 0,10-0,20 ; 0,20-0,40 ; 0,40-0,60 \mathrm{~m}$.

Na figura 8, embora os valores se alterem devido ao crescimento das árvores, nota-se semelhança na distribuição espacial, confirmando o que já foi discutido sobre o crescimento bastante uniforme das árvores. Relacionando-se com os mapas de propriedades físicas de solo, não se observa muita semelhança entre eles, apesar de que na parte superior direita da área ocorreram maiores valores do perímetro do caule coincidindo com mesmo local de menores valores de densidade do solo, indicando que o solo mais denso pode ter prejudicado o espessamento do caule da seringueira.

Houve distribuição espacial contínua do crescimento das árvores de seringueira ao longo do tempo e estreita correlação com densidade do solo, como mostram os mapas da figura 7i-k em comparação com os da figura 8, em que locais menos densos, em geral, proporcionaram maior perímetro do caule da seringueira. 
(a) $05 / 1996$

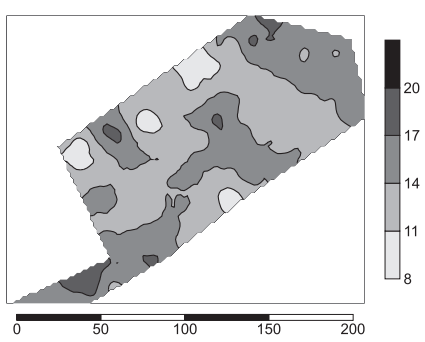

(c) $11 / 1997$

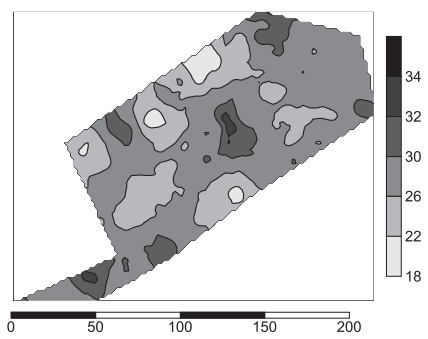

(e) $11 / 1998$

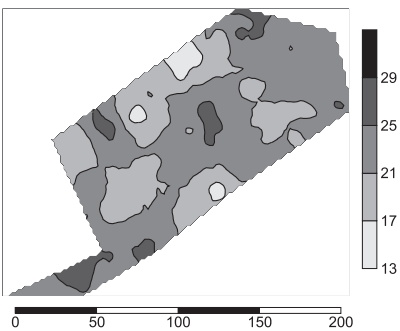

(b) $04 / 1997$

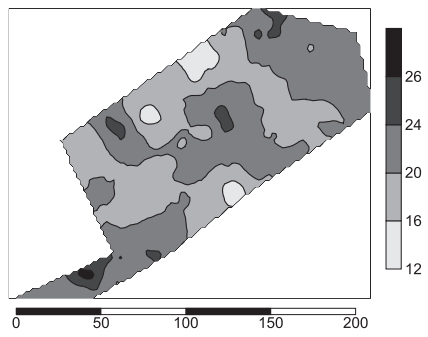

(d) $05 / 1998$

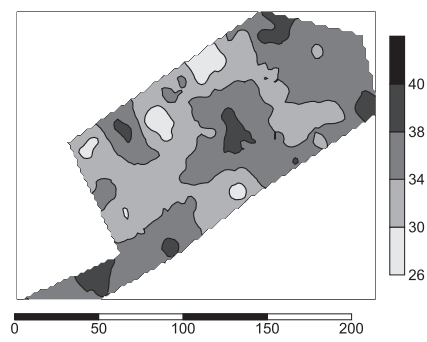

(g) $11 / 1999$ (f) $05 / 1999$

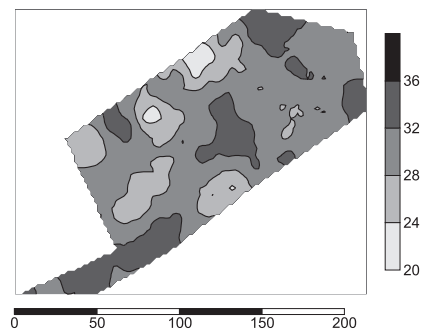

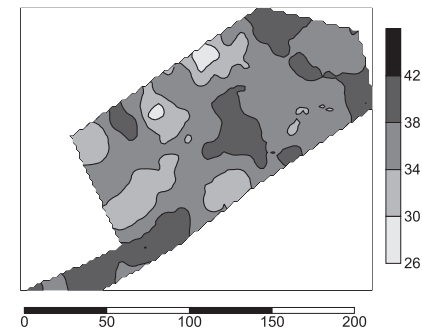

Figura 8. Mapa de isolinhas para perímetro do caule $(\mathrm{cm})$ da seringueira de 1997 a 1999.

\section{CONCLUSÕES}

1. Houve dependência espacial para todas as propriedades físicas do solo variando de moderada a forte com alcance de dependência espacial de 15 a $90 \mathrm{~m}$.

2. Com a infiltração saturada de água do solo ocorreu dependência espacial, porém não houve relação com as épocas e as profundidades amostradas. Os altos valores de densidade do solo e também de microporosidade na camada de 0,20-0,40 $m$ indicaram compactação nesta camada.

3. O perímetro do caule das árvores de seringueira foi inversamente proporcional à densidade do solo.

\section{REFERÊNCIAS}

APABOR. Informativo APBOR, Associação Paulista de Produtores e Beneficiadores de Borracha, Ano IX, n. ${ }^{\circ} 50$ Junho / 2003.
CARDOSO, M. Instruções para a cultura da seringueira. Campinas: Instituto Agronômico, 1989. 50p. (Boletim, 196)

CAMARGO, O.A.; MONIZ, A.C.; JORGE, L.A.; VALADARES, J.M.A.S. Métodos de análise química, mineralógica e física de solos do Instituto Agronômico de Campinas. Campinas: Instituto Agronômico, 1986. 93p. (Boletim Técnico, 106)

CENTURION, J.F.; ROQUE, C.G.; CENTURION, M.A.P.C.; PRADO, R.M.; Manejo mecânico e cultura de cobertura na entrelinha da seringueira (Pb $235 \mathrm{E}$ Rrim 701) e os atributos físicos de um Latossolo Vermelho no Planalto Paulista. Revista Árvore, v.28, p.7-13, 2004.

EMPRESA BRASILEIRA DE PESQUISA AGROPECUÁRIAEMBRAPA. Centro Nacional de Pesquisa de Solos. Sistema Brasileiro de Classificação de Solos. 2.ed. Rio de Janeiro, 2006. 306p.

JORGE, L.A.B. Manejo Florestal: Guia de Estudo. Botucatu, Departamento de Recursos Naturais, Faculdade de Ciências agronômicas, Universidade Estadual Paulista, 2005. 208p.

JOURNEL, A.G.; HUIJBREGTS, J. Mining Geostatistics. London, New York, San Francisco: Academic Press, 1978. 600p. 
GOLDEN SOFTWARE. Surfer 7.0 Users Guide: Contouring and 3D surface mapping for scientists engineers. Golden Software, Golden, 1999. 619p.

GREGO, C.R.; VIEIRA, S.R. Variabilidade espacial de propriedades físicas do solo em uma parcela experimental. Revista Brasileira de Ciência do Solo, v.29, p.169-177, 2005.

GUEDES FILHO, O. Variabilidade espacial e temporal de mapas de colheita e atributos do solo em um sistema de semeadura direta. 2009. 97f. Dissertação (Mestrado em Agronomia) - Instituto Agronômico - IAC, Campinas.

NIELSEN, D.R.; BIGGAR, J.W.; ERH, K.T. Spatial variability of field-measured soil water properties. Berkeley, v.42, p.215$260,1973$.

NUERNBERG, N.J.; STAMMEL, J.G.; CABEDA, M.S.V. Efeito da sucessão de culturas e tipos de adubação em características físicas de um solo da Encosta Basáltica SulRiograndense. Revista Brasileira de Ciência do Solo, v.10, p.185-190, 1986.

SIQUEIRA, G.M. Variabilidade de atributos físicos do solo determinados por métodos diversos. 2006. 182f. Dissertação (Mestrado) - Instituto Agronômico-IAC, Campinas. SNEDECOR, G.W.; COCHRAN, W.G. Statistical methods. 6.ed. Ames: Iowa State University Press 1967. 593p.

SOUZA, Z. M.; ALVES, M.C. Movimento de água e resistência à penetração em um Latossolo Vermelho distófico de cerrado. Revista Brasileira de Engenharia Agrícola e Ambiental, v.7, p.18-23, 2003.

VIEIRA, S.R. Permeâmetro: novo aliado na avaliação de manejo do solo. O Agronômico, v. 47-50, 1995-1998.

VIEIRA, S.R. Geoestatística em estudos de variabilidade espacial do solo. In: NOVAIS, R.F., ALVAREZ, V.H.; SCHAEFER, G.R. (Ed.). Tópicos em Ciência do solo. Viçosa: Sociedade Brasileira de Ciência do solo, 2000 v.1,. p.1-54.

VIEIRA, S.R.; NIELSEN, D.R.; BIGGAR, J.W. Spatial variability of field-measured infiltration rate. Soil Science Society of America Journal, v.45, p.1040-1048, 1981.

VIEIRA, S.R.; HATFIELD, J.L.; NIELSEN, D.R. e BIGGAR, J.W. Geostatistical theory and application to variability of some agronomical properties. Hilgardia, v.51, p.1-75, 1983.

VIEIRA, S.R., MILLETE, J., TOPP, G.C., REYNOLDS, W.D. Handbook for geostatistical analysis of variability in soil and climate data. In: ALVAREZ, V.H.; SCHAEFER, G.R.; BARROS, N.F.; MELLO, J.W.V.; COSTA, L.M. (Ed). Tópicos em Ciência do solo. Viçosa: SBCS, 2002. v.2, p.1-45.

ZIMBACK, C.R.L. Análise espacial de atributos químicos de solo para o mapeamento da fertilidade do solo. 2001, 114 p. Tese (Livre docência). Faculdade de Ciências Agronômicas, Botucatu. 